\title{
A PLS-SEM Approach to Connect Fertility, GDP, and Childhood Mortality with Female life Expectancy (FLE) in Bangladesh
}

\author{
Md. Mortuza Ahmmed, Md. Ashraful Babu, Mohammad Abdul Hoque, M. Mostafizur Rahman
}

\begin{abstract}
Reasonable number of studies on the effect of Female life expectancy (FLE) upon the quality of women's lives in developed countries has been done. Bangladesh lacks such a study. We explore to see the effect of decreasing fertility and childhood mortality rates on FLE in Bangladesh and evaluate the potential impact of the demographic transition on GDP. Also, we investigate the trends and patterns of different factors from 1995 to 2018. Partial Least Squares-Structural Equation Modeling (PLS-SEM) is functioned to fit an appropriate model to link fertility, GDP, and childhood mortality with FLE. The significance of the relationships has also been assessed. Results indicate that declines in fertility and childhood mortality have made significant improvements in FLE. The prospects of demographic transition due to fertility decline have been analyzed and challenges to achieve it are highlighted.
\end{abstract}

Index Terms-Female life expectancy, fertility, mortality, structural equation modeling, confirmatory factor analysis, demographic transition.

\section{INTRODUCTION}

Maternal death tends to escalate with the rising number of childbirths delivered by the mother [1]. The health status of both the mother and her children are important aspects for improved Female Life Expectancy (FLE), and hence for the development of a nation [2]. Low deployment of the available health care services is one of the foremost reasons behind infant and maternal mortality in Bangladesh [3].

\section{Md. Mortuza Ahmmed}

Assistant Professor,

Department of Mathematics,

American International University-Bangladesh

Email: mortuza123034@gmail.com

Md. Ashraful Babu

Assistant Professor,

Department of Quantitative Sciences,

International University of Business Agriculture and Technology

Email: ashraful388@gmail.com

Mohammad Abdul Hoque

Professor,

BRAC Business School

BRAC University

Email: abdul.hoque@bracu.ac.bd

\section{Mostafizur Rahman}

Associate Professor,

Department of Mathematics,

American International University-Bangladesh

Email: mostafiz.math@aiub.edu
Moreover, poor nutrition, inadequate health care, and a large number of frequent pregnancies lead to higher maternal mortality [4]. Data on Gross Domestic Product (GDP) growth rate and infant mortality rate for the period 1986 to 2004 collected from 59 developing countries revealed a strong negative association between them $[5,6,7]$. Over the last two decades, the improvement of maternal and child health including female life expectancy has been continuously drawing the attention of several public health agendas across nations $[8,9,10]$. Neonatal deaths have been accounted for most of the infant deaths from 1995 to 2018 around the world $[11,12]$. Early childhood mortality rates in Bangladesh have dropped significantly in this period $[13,14,15]$. Although incredible development in achieving Millennium Development Goals (MDGs) has been shown by the Bangladesh government, further improvement regarding this is needed to abide by the Sustainable Development Goal 3(SDG 3) [16,17].

By employing both the cross-sectional and trend analysis, a high negative association concerning economic growth and various categories of childhood mortality rates has been well established in several studies [18,19,20,21,22,23]. Economic stagnations and malnutrition are significantly correlated amid the mothers and their kids in developing nations. As a result, the financial shocks have been associated with the increase of maternal and early childhood mortality rates in those countries [19]. Thus, improvement of maternal and child health care promises further development of living standard of people, level of nutrition, public and private health care services, sanitation, supply of safe water, and so on, which ultimately ensure the higher life expectancy of women [21,24]. Besides, FLE is considered as one of the indicators of measuring the quality of life of women $[25,26]$. A reasonable number of studies on FLE in developed nations have validated this notion [27,28]. Generally, low infant and child mortality rates result in higher life expectancy for females $[28,29,30]$. The higher expectation of life is associated with a lower under-5 mortality rate too $[31,32,33,34]$. Several studies concerning reproductive and public health care explain how the decline in total fertility rate (TFR) enhances women's life expectancy better [35,36,37,38,39]. The Infant Mortality Rate (IMR) is excessive in Bangladesh as well as in many other developing countries, despite their continuous decline during the last two decades [40]. Besides, the risk of maternal deaths has been 
relegated by continuous fertility decline, resulting in higher FLE [41]. The main purpose of this study is to carry out a detailed study on the effect of fertility and childhood mortality decline on female life expectancy in Bangladesh. So far the authors' knowledge goes, this would be a pioneering approach that applies PLS-SEM to connect the demographic variables with the life expectancy of females in Bangladesh. This type of study will clearly show the intensity of improvement in FLE following the decreases in different mortality rates, which will be helpful for the government in adopting various measures for achieving the sustainable development goal.

\section{METHODOLOGY}

\section{A. Graphical Representation}

To understand the patterns and trends of the variables under study from 1995 to 2018, graphical representations of them have been performed.

\section{B. Descriptive Analysis}

To describe the basic features of the variables under study, selected summary statistics regarding the concerned variables within their corresponding ranges have been calculated.

\section{Partial Least Squares-Structural Equation Modeling (PLS-SEM)}

PLS-SEM is a method of modeling with no assumptions regarding data distribution [42]. It evaluates the associations among the variables and validates how well the model describes the focus constructs. It can be used when the size of the sample is small, desired projection accuracy is utmost, and the exact specification of the model cannot be guaranteed [43].

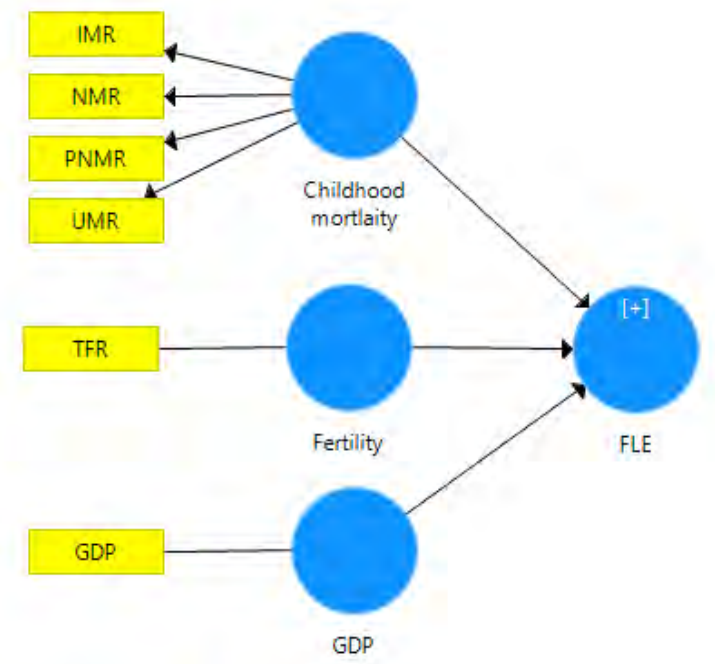

Fig. 1. Framework of the considered PLS-SEM model

The PLS-SEM model for this study has considered four observed variables as demonstrated in Figure 1. Childhood mortality (combination of IMR, NMR, PNMR, UMR), TFR, and GDP has been used as input variables while FLE is the output variable.

\section{Research Hypotheses}

$\mathrm{H}_{1}$ : Childhood mortality affects FLE

$\mathrm{H}_{2}$ : Fertility impacts FLE

$\mathrm{H}_{3}$ : GDP influences FLE

\section{E. Source of the Data}

The last Sample Vital Registration System 2018 (SVRS) managed by the Bangladesh Bureau of Statistics (BBS) is utilized for extracting the data concerning all the variables considered in this study for the period 1995 to 2018 [14].

\section{F. Analytical Tools}

The variables have been selected taking the subsequent literature review into account for Bangladesh perspective. SmartPLS software version 3.3.3 has been used to perform all the required statistical analyses.

\section{RESULTS AND DISCUSSION}

\section{A. Fertility}

The TFR against years from 1995 to 2018 of Bangladesh is plotted in Figure 1. It can be observed that TFR over the years has decreasing trend overall. A sharp decrease in TFR from 1996 to 2001 is observed. During this period, the Bangladesh government implemented the family planning programs effectively by utilizing mass media campaigns for the encouragement of married couples to use contraceptives by creating awareness among them. As a result, the overall contraceptive prevalence rate increased from 44.6 percent to 53.8 in that period [16], resulting in a steep decline in TFR. Low TFR is related to better maternal and child health care as a mother with lesser children can focus on their children more effectively. This has resulted due to improved life and health of their children as well as themselves.

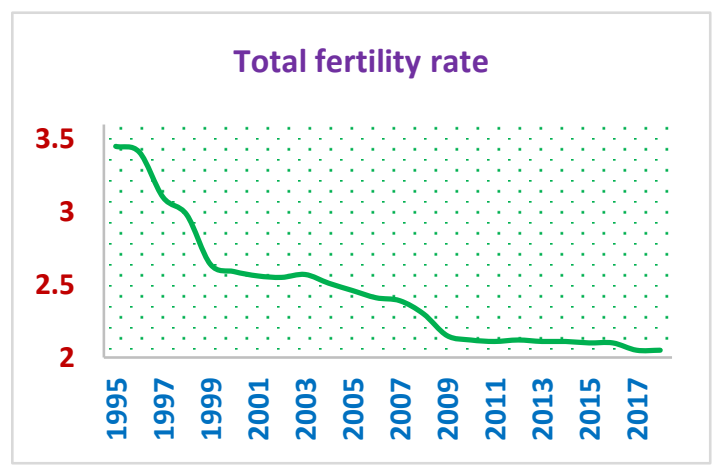

Fig. 2. TFR in Bangladesh between 1995 - 2018 [Source: SVRS]

\section{B. Childhood Mortality}

The trends in childhood mortality rates in Bangladesh involving NMR, PNMR, IMR, and CMR from1995 to 2018 in Bangladesh are shown in Figure 2. As expected, a declining trend in each of the categories over the considered period has been observed. It can be perceived that the PNMRs are just about one-third of NMRs, and IMR, NMR, and PNMR have been dropped in percentage by 56,46 , and 71 respectively in the last two decades. A noticeable point spotted in Figure 2 is the fact that NMR has been declined by 
1.5 percent since 2000 which is slower than its counterparts in IMR $(2.8 \%)$. A probable reason could be the lack of postnatal care provided to women.

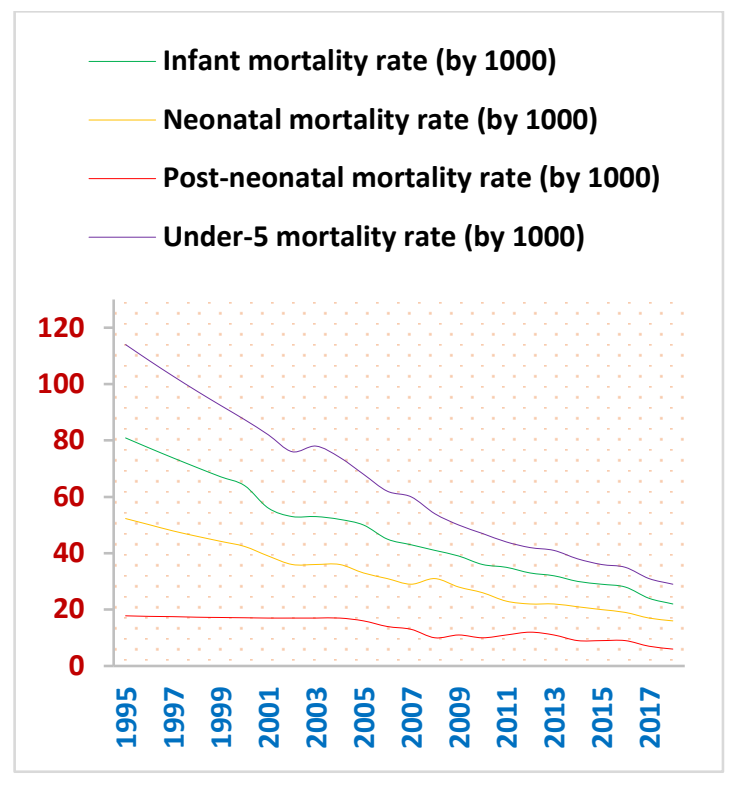

Fig. 3. Childhood mortality rates in Bangladesh over 1995 to 2018 [Source: SVRS]

\section{Economic Growth and Female Life Expectancy}

The trends in GDP growth rate (\%) in Bangladesh from 1995 to 2018 can be visualized in Figure 3. On average a growing trend with little fluctuations is visible over the last two decades. Ever the highest GDP growth rate was achieved in 2018 whereas the average GDP growth rate was nearly six percent for the last two decades in Bangladesh. Most probably the growth rate was accelerated by increasing exports and remittances, national and foreign investments, industrialization, women empowerment, enhanced participation rates in all levels of education, job opportunities in both the public and the private sectors, improved communication systems, higher capacity, and productivity in power sectors, and of course, the political stability along with good governance.

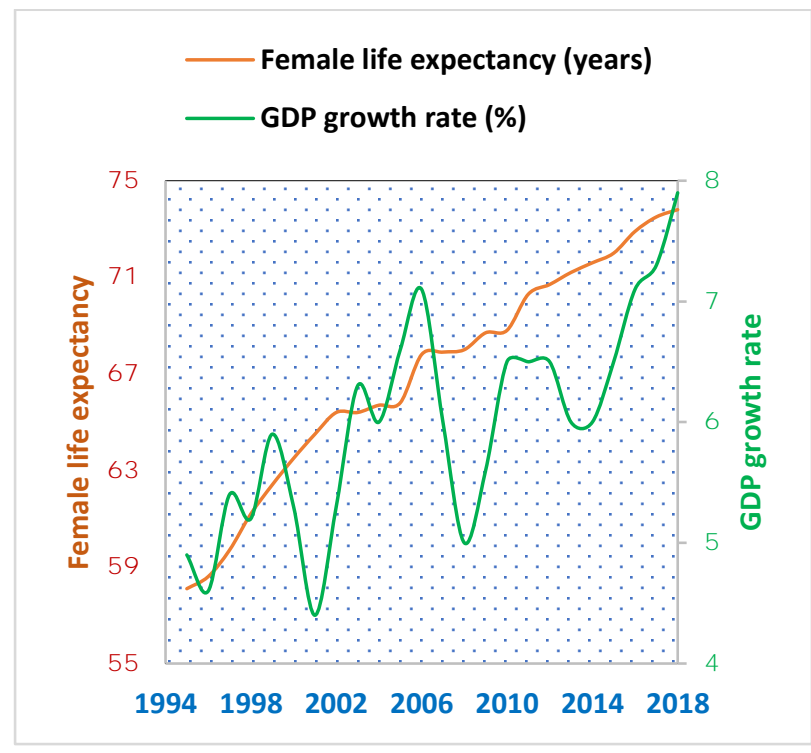

Fig. 4. GDP and FLE in Bangladesh from 1995 to 2018 [Source: SVRS]

A sharp rising trend of female life expectancy in Bangladesh over the last two decades is reflected in Figure 3. Starting with the expectation of life of 58.1 years back in 1995, an average annual increase of 0.65 years for the last twenty-four years resulted in 73.8 years of female life expectancy in 2018. Although the GDP growth rate dropped in some years, the female life expectancy continued to increase in those years, indicating that the female life expectancy does not depend on the GDP growth rate only. Findings of the study conducted by Becker's study [44] support this hypothesis. Moreover, Murphy and Topel [45] found in their study that a decline in mortality rates would extend the individual lifetime horizon.

TABLE 1

DIFFERENT ASPECTS OF RELIABILITY AND VALIDITY ANALYSIS FOR PLS-SEM

\begin{tabular}{|c|c|c|c|c|c|}
\hline & . & Childhood Mortality & FLE & TFR & GDP \\
\hline \multirow{4}{*}{ Correlation analysis } & Childhood Mortality & 1 & -0.989 & 0.932 & -0.732 \\
\hline & FLE & -0.989 & 1 & -0.953 & 0.748 \\
\hline & TFR & 0.932 & -0.953 & 1 & -0.673 \\
\hline & GDP & -0.732 & 0.748 & -0.673 & 1 \\
\hline \multirow{4}{*}{ Discriminant validity } & Childhood Mortality & 0.984 & & & \\
\hline & FLE & -0.989 & 1 & & \\
\hline & TFR & 0.932 & -0.953 & 1 & \\
\hline & GDP & -0.732 & 0.748 & -0.673 & 1 \\
\hline \multirow{3}{*}{ VIF } & Childhood Mortality & & 6.014 & & \\
\hline & TFR & & 4.678 & & \\
\hline & GDP & & 2.156 & & \\
\hline \multirow{3}{*}{ Reliability and validity } & Cronbach's Alpha & 0.989 & 1 & 1 & 1 \\
\hline & Composite Reliability & 0.992 & 1 & 1 & 1 \\
\hline & Average Variance Extracted (AVE) & 0.968 & 1 & 1 & 1 \\
\hline
\end{tabular}




\section{Reliability and Validity Analysis for PLS-SEM}

The reliability and validity of the proposed PLS-SEM model for the study have been assessed through selected approaches as shown in Table 1. The bivariate relationships between the variables have been monitored through correlation analysis. Results of correlation analysis show that GDP is negatively correlated with childhood mortality $(r=$ $-0.732)$ and fertility $(r=-0.673)$. The rising trend of GDP in the country as illustrated earlier in Figure 4 could be a justification for witnessing the negative correlations. However, a positive correlation has been detected between GDP and FLE $(r=0.748)$ which means that a rise in GDP would result in a rise in FLE. Besides, FLE is observed to have a negative correlation with both childhood mortality $(r=-0.989)$ and fertility $(r=-0.953)$ which means that a fall in childhood mortality and fertility would result in a rise in FLE. Estimated scores of Cronbach alpha are 0.989 for childhood mortality and 1 for the remaining variables. According to Nunnally and Bernstein, Cronbach alpha's accepted value to determine the reliability is above 0.70 [46]. Hence, Cronbach alpha scores of all the variables under study are reliable. Discriminant and convergent validity of the model have been established by Confirmatory Factor Analysis (CFA). The convergent method evaluates construct validity considering the multitrait-multimethod matrix (MTMM) as mentioned by Campbell and Fiske [47]. According to them, the standard for the composite reliability scores to be accepted is above 0.70 . The composite reliability scores have been estimated as 0.992 for childhood mortality and 1 for the remaining variables. According to Anonymous, the accepted score of Average Variance Extracted (AVE) is 0.50 or more [48]. The AVE scores have been calculated as 0.968 for childhood mortality and 1 for the remaining variables. The discriminant validity describes the measurement of constructs to provide a basis of discrimination among the variables under study. The multicollinearity of the variables is checked by Variation Influence Factor (VIF) score. The acceptable limit of VIF score is less than 10 according to Henseler et al. [49]. From Table 1, we can see that all the VIF scores are less than 10 indicating that there is no presence of multicollinearity between the formative constructs of the study.

TABLE 2

DESCRIPTIVE STATISTICS

\begin{tabular}{|c|c|c|c|c|c|}
\hline Variables & Minimum & Maximum & Skewness & Kurtosis & Coefficient of Variation \\
\hline Childhood Mortality & 1.70 & 80.90 & -0.213 & -1.718 & $33.74 \%$ \\
\hline FLE & 58.10 & 73.80 & -0.381 & -0.780 & $6.99 \%$ \\
\hline TFR & 2.05 & 3.45 & 1.203 & 0.776 & $16.88 \%$ \\
\hline GDP & 4.40 & 7.90 & 0.139 & -0.397 & $14.77 \%$ \\
\hline
\end{tabular}

\section{E. Descriptive Statistics}

The descriptive statistics regarding the selected variables under study have been encapsulated in Table 2. Coefficient of variation results shows that childhood mortality has the maximum variation among the variables (33.74\%), followed by TFR (16.88\%) and GDP (14.77\%). The FLE is observed to have the least variation among all (6.99\%). Findings regarding skewness show that childhood mortality and FLE are negatively skewed which means the respective averages of these two variables are lower than the corresponding median values referring to a longer or fatter tail on the left side of the relevant distributions. TFR and GDP, on the other hand, show positive skewness which implies the corresponding averages of these two variables are higher than the respective median values indicating a longer or fatter tail on the right side of the corresponding distributions. Distributions of all the variables are platykurtic showing kurtosis values less than 3 which means the distributions encompass a smaller number of extreme values.

TABLE 3

PLS-SEM FINAL OUTCOMES

\begin{tabular}{|c|c|c|c|c|}
\hline Hypotheses & Path Coefficients $(\boldsymbol{\beta})$ & Standard Deviation & $\boldsymbol{t}$-statistic & $\boldsymbol{p}$ - value \\
\hline H$_{\mathbf{1}}$ : Childhood Mortality - > FLE & -0.723 & 0.085 & 8.549 & 0.000 \\
\hline $\mathbf{H}_{2}:$ TFR - > FLE & -0.242 & 0.085 & 2.846 & 0.004 \\
\hline H $_{3}$ : GDP - > FLE & 0.056 & 0.034 & 1.627 & 0.104 \\
\hline
\end{tabular}

\section{F. PLS-SEM Outcomes}

The major outcomes of the proposed PLS-SEM model are summarized in Table 3 . Findings of $\mathrm{H}_{1}$ statistically verify that childhood mortality has a significant negative effect on FLE, confirmed by path coefficient $\beta=-0.723$ and $p-$ value $=0.000$. The results are supported by the outcomes of the studies conducted by Haider et al. [3] and Murphy and
Topel [45]. Likewise, the findings of $\mathrm{H}_{2}$ statistically verify that TFR has a significant negative effect on FLE, confirmed by path coefficient $\beta=-0.242$ and $p-$ value $=0.004$. The result is supported by findings of several other studies where it was observed that females with fewer children live longer than those having more children $[35,37,38]$. The 
falling fertility trend lifts FLE as females having fewer pregnancies are less likely to be exposed to maternal death [38]. The path coefficient $\beta=0.056$ for GDP implies a positive effect on FLE which accords to the decisions of the

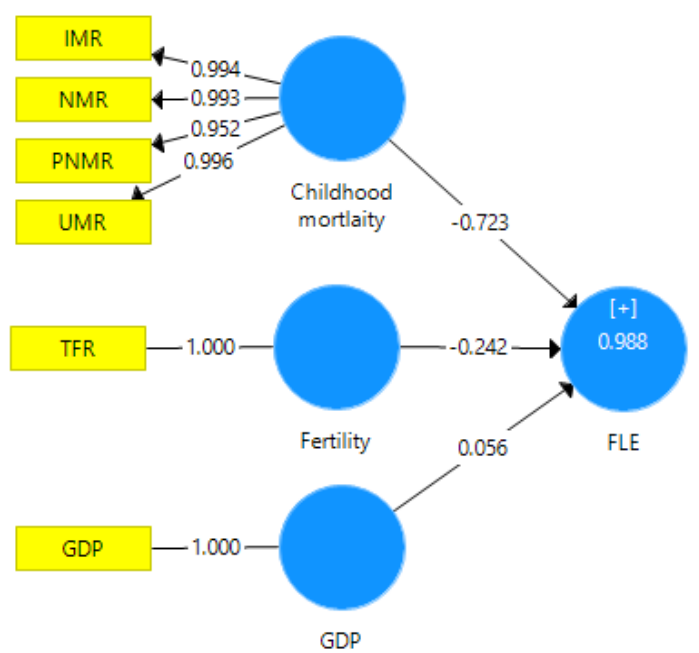

Fig. 5. PLS-SEM layout of factor loadings and path coefficients

The PLS-SEM layout of the factor loadings together with the path coefficients can be seen through Figure 5. The model using the path coefficients can be written as:

$$
\begin{gathered}
E(F L E)=0.056(G D P)-0.723(\text { Childhood Mortality }) \\
-0.242(T F R)
\end{gathered}
$$

According to Campbell and Fiske, the benchmark score for factor loadings is 0.60 [47]. All the factor loadings of our model are observed to be well above that acceptable level.

\section{G. Demographic transition}

The declining fertility trend in Bangladesh has resulted in shifts in the educational empowerment of women, the age structure of the country; the percentage of the working-age population is on the rise, while the proportion of the dependent-age population has been decreasing continuously. This demographic transition has been pursued in relegating death rates by managing pandemic and infectious diseases [50]. Thus, such a transition plays a vital role in reducing death from pandemics like coronavirus disease COVID-19 in a nation like Bangladesh. This is what the demographers define as a demographic dividend. The working-age population with immense strength and committed promise for imminent leadership opens a great opportunity for Bangladesh. If the country fails to avail this opportunity with immediate effect, this energetic group of population would then become a burden for the nation. To reap advantage from this opportunity, the policymakers should focus on issues like poverty reduction, improvement of public health care, the establishment of a favorable environment for investment, creation of more job opportunities, safeguarding of gender equality in every sector, and so on. study conducted by Mahyar [22], where it was observed that a one percent rise in GDP growth rate led to nearly 0.01 percent increase in life expectancy in the next period.

\section{CONCLUSION}

It has been demonstrated through this study that fertility and childhood mortality declines have a positive effect on female life expectancy in Bangladesh. We have highlighted the positive impact of the demographic transition in Bangladesh, its prospect, and challenges to achieve it. The concerned policymakers should adopt more fertility and childhood mortality reduction programs, and the government should invest more in prioritizing these programs. Proper attention should be given to the assessment of how better maternal and child health care initiatives affect the national development of our country. Countries investing more in maternal and child health care are most likely to have a healthier population, and subsequently will be more productive for the upcoming generations. It is obvious from the above discussion that the state of maternal and child health has upgraded to a great deal over the studied period1995 to 2018, due to the progress of the accompanying factors. But still, there are some related areas needed to be upgraded for better FLE. Our endeavor should be for the smallest possible childhood mortality rate. Also, using the multiple regression model the female life expectancy from 2019 to 2028 for Bangladesh has been projected. Applying this model, the female life expectancy for the next ten years is found to be increasing almost linearly overall. Both the government and the NGOs must adopt more effective initiatives in this regard. Bangladesh showed incredible development in achieving Millennium Development Goals. Our government is committed to implement Sustainable Development Goals successfully as well. In achieving this goal maternal and child health status must be improved further to comply with SDG 3. If improved maternal and child health programs are properly designed and executed, they will certainly overcome the negative effects of socioeconomic inequalities considerably. Here we have investigated the effect of reduction in various mortality rates on the female life expectancy in Bangladesh. Nevertheless, some other factors like female literacy rate, safe delivery practices, etc. might have notable effects on female life expectancy. Due to the unavailability of the relevant national-level data for these variables, we have not been able to include them in our study. Hence, there is a room for additional research on the topic by including those types of variables. 


\section{REFERENCES}

[1] Hurt LS, Ronsmans C, and Thomas SL. The effect of number of births on women's mortality: Systematic review of the evidence for women who have completed their childbearing. Population Studies: A Journal of Demography 2006;60(1):55-71.

[2] Németh L and Missov TI. Adequate life-expectancy reconstruction for adult human mortality data. PloS one 2018;13(6): e0198485.

[3] Haider M, Rahman M, Moinuddin M, Rahman A, Ahmed S, Khan M. () Impact of maternal and neonatal health initiatives on inequity in maternal health care utilization in Bangladesh. PLoS ONE 2017;12(7):1-15.

[4] BMMS. Bangladesh Maternal Mortality and Health Care Survey 2010. National Institute of Population Research and Training (NIPORT), Dhaka, MEASURE Evaluation, UNC-CH, USA icddr,b; 2010

[5] Baird S, Friedman J, Schady N. Aggregate income shocks and infant mortality in the developing world. Review of Economics and statistics 2011;93(3):847-856.

[6] Baptista EA, Queiroz BL. The relation between cardiovascular mortality and development: Study for small areas in Brazil, 2001-2015. Demographic Research 2019;41:1437-1452.

[7] Kembo J, Ginneken JKV. Determinants of infant and child mortality in Zimbabwe: Results of multivariate hazard analysis. Demographic Research 2009;21:367384

[8] Vollmer, S., Harttgen, K., Subramanyam, M.A., Finlay, J., Klasen, S. and Subramanian, S.V., 2014. Association between economic growth and early childhood undernutrition: evidence from 121 Demographic and Health Surveys from 36 low-income and middle-income countries. The lancet global health, 2(4), pp.e225-e234.

[9] Nishiyama A. Economic growth and infant mortality in developing countries. The European Journal of Development Research 2011;23(4):630-647.

[10] Gamella, J.F. and Carrasco-Muñoz, E.M., 2017. The decline of infant and child mortality among Spanish Gitanos or Calé (1871-2005) A micro demographic study in Andalusia. Demographic Research, 36, pp.945-988.

[11] Handbook of Vital Statistics Systems and Methods. Volume 1: Legal, Organizational and Technical Aspects, United Nations Studies in Methods, Glossary. Series F, No. 35. United Nations, New York 1991.

[12] Hessol A, Fuentes-Afflick E. Ethnic differences in neonatal and post-neonatal mortality. Pediatrics 2005;115(1):e44-e51.

[13] Baqui A, Ahmed S, Arifeen S, Darmstadt G, Rosecrans A, Mannan I, et al. Effect of timing of first post-natal care home visit on neonatal mortality in Bangladesh: an observational cohort study. British Medical Journal 2009;339(7718): $1-6$

[14] Bangladesh Sample Vital Registration System. Bangladesh Bureau of Statistics, Dhaka; 2018.

[15] Bhatia S. Patterns and causes of neonatal and postneonatal mortality in rural Bangladesh. Studies in family planning 1989;20(3):136-146.

[16] BDHS. Bangladesh demographic and health survey. National Institute of Population Research and Training (NIPORT), Dhaka; 2014

[17] Gupta J, Vegelin C. Sustainable development goals and inclusive development. International environmental agreements: Politics, law and economics 2016;16(3):433448.

[18] Erdogan E, Ener M, Arıca F. The strategic role of infant mortality in the process of economic growth: An application for high-income OECD countries. ProcediaSocial and Behavioral Sciences 2013;99:19-25.

[19] Bohk, C. and Rau, R., 2016. Impact of economic conditions and crises on mortality and its predictability. In Social Demography Forschung an der Schnittstelle von Soziologie und Demografie (pp. 271-294). Springer VS, Wiesbaden.
[20] Kirigia M, Oluwole D, Mwabo M, Gatwiri D, Kainyu H. Effects of maternal mortality on gross domestic product (GDP) in the WHO African region. African journal of health sciences 2006;13(1):86-95.

[21] Onarheim H, Iversen H, Bloom E. Economic benefits of investing in women's health: a systematic review. PloS one 2016;11(3):e0150120.

[22] Mahyar H. Economic growth and life expectancy: The case of Iran. Studies in Business and Economics 2016;11(1):80-87.

[23] Neal S, Falkingham J. Neonatal death and national income in developing countries: will economic growth reduce deaths in the first month of life? International Journal of Population Research 2014; Article ID 989485.

[24] Kapungwe A. Quality of child health care and under-five mortality in Zambia: Demographic Research 2005;12:301-322.

[25] Robine JM, Romieu I, Cambois E. Health expectancy indicators. Bulletin of the World Health Organization 1999;77(2):181.

[26] Bergeron-Boucher MP, Ebeling M, Canudas-Romo V. Decomposing changes in life expectancy: Compression versus shifting mortality. Demographic Research 2015;3:391-424.

[27] Ho JY, Hendi AS. Recent trends in life expectancy across high-income countries: a retrospective observational study. $b m j$ 2018;362:k2562.

[28] Saarela J, Finnäs F. Infant mortality and ethnicity in an indigenous European population: Novel evidence from the Finnish population register. Scientific reports 2014;4:4214

[29] Reidpath D, Allotey P. Infant mortality rate as an indicator of population health. Journal of Epidemiology \& Community Health 2003;57(5):344-346.

[30] Shapiro D, Tenikue M. Women's education, infant and child mortality and fertility decline in rural and urban subSaharan Africa. Demographic Research 2017;37:669708.

[31] Liu L, Oza S, Hogan D, Chu Y, Perin J, Zhu J, et al. Global, regional, and national causes of under-5 mortality in 2000-15: an updated systematic analysis with implications for the Sustainable Development Goals. The Lancet 2016;388(10063):3027-3035.

[32] Woldeamanuel T. Socioeconomic, Demographic, and Environmental Determinants of Under-5 Mortality in Ethiopia: Evidence from Ethiopian Demographic and Health Survey 2016, Child Development Research 2019.

[33] Mejía-Guevara I, Zuo W, Bendavid E, Li N, Tuljapurkar S. Age distribution, trends, and forecasts of under-5 mortality in 31 sub-Saharan African countries: A modeling study. PLoS medicine 2019;16(3):e1002757.

[34] Hill K, You D, Inoue M, Oestergaard Z. Child mortality estimation: accelerated progress in reducing global child mortality, 1990-2010. PLoS medicine 2012;9(8):e1001303.

[35] Kuningas M, Altmäe S, Uitterlinden AG, Hofman A, Duijn CM, Tiemeier $\mathrm{H}$. The relationship between fertility and lifespan in humans. Age 2011;33(4):615-622.

[36] Hendi AS. Trends in education-specific life expectancy, data quality, and shifting education distributions: A note on recent research. Demography 2017;54(3):1203-1213.

[37] Kaptijn R, Thomese F, Liefbroer AC, Van Poppel F, Van Bodegom D, Westendorp RG. The trade-off between female fertility and longevity during the epidemiological transition in the Netherlands. PloS one 2015;10(12):e0144353.

[38] Stoebenau, K., Pande, R. and Malhotra, A., 2013. Has Fertility Decline Contributed to Improvements in Women's Lives?. ICRW.

[39] Modig K, Talbäck M, Torssander J, Ahlbom A. Payback time? Influence of having children on mortality in old age. J Epidemiol Community Health 2017;71(5):424430 . 
[40] Islam S, Rahaman M, Aziz S, Rahman M, Munshi H, Patwari Y. Infant mortality in rural Bangladesh: an analysis of causes during neonatal and post-neonatal periods. Journal of tropical pediatrics 1982;28(6:294-298.

[41] Website of Organization for Economic Co-operation and Development. https://data.oecd.org/healthstat/lifeexpectancy-at-birth.htm (Accessed on October 26, 2019).

[42] Sarstedt, M. and Cheah, J.H., 2019. Partial least squares structural equation modeling using SmartPLS: a software review.

[43] Hair, J.F., Risher, J.J., Sarstedt, M. and Ringle, C.M., 2019. When to use and how to report the results of PLSSEM. European business review.

[44] Becker GS, Philipson TJ, Soares RR. The quantity and quality of life and the evolution of world inequality. American Economic Review 2005;95(1):277-291.

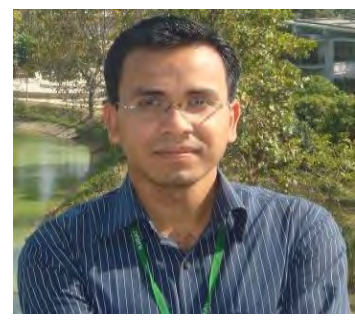

Md. Mortuza Ahmmed did his B.Sc. and M.Sc. in Statistics, Biostatistics and Informatics from University of Dhaka in 2007 and 2009 respectively. He is currently working as an Assistant Professor in Statistics under Department of Mathematics,

American International University - Bangladesh. His research interests include demography, education, epidemiology etc. He has published several articles in local and international peer reviewed journals and conferences.

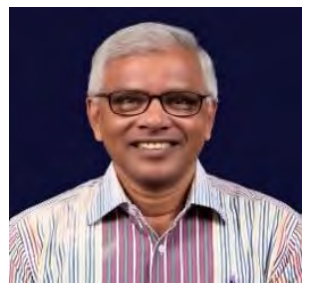

Dr. Mohammad Abdul Hoque is a Professor of Brac Business School of Brac University, Bangladesh. He had been awarded the degrees of Ph. D. (1994) and M. Sc. (Res.) (1991) in Management Science from Lancaster University Management School, England VIA Common Wealth scholarship. He worked as Associate Professor (2008 - 2016) at the Department of Mathematical and Computing Sciences of Universiti Brunei Darussalam. Also, Prof. Dr. Hoque worked as Senior Lecturer (2002 - 2004) at the School of Mathematical Sciences, Universiti Sains Malaysia. Moreover, he worked at the Department of Mathematics (Lecturer - Professor) of Jahangirnagar University (1987 - 2002), Dhaka, Bangladesh. In addition, he taught as a tutor at Lancaster University for one year. He has extensive research experience in Supply Chain Management, Operations Research, Public Health Management, etc.
[45] Murphy, K.M. and Topel, R.H., 2006. The value of health and longevity. Journal of Political Economy, 114(5), pp.871-904

[46] Nunnally, J. and Bernstein, I., 1994. Psychometric Theory 3rd edition (MacGraw-Hill, New York).

[47] Campbell, D.T. and Fiske, D.W., 1959. Convergent and discriminant validation by the multitrait-multimethod matrix. Psychological Bulletin, 56(2), p.81.

[48] Management Association ed., 2018. Technology Adoption and Social Issues: Concepts, Methodologies, Tools, and Applications: Concepts, Methodologies, Tools, and Applications. IGI Global.

[49] Henseler, J., Ringle, C.M. and Sarstedt, M., 2015. A new criterion for assessing discriminant validity in variancebased structural equation modeling. Journal of the academy of marketing science, 43(1), pp.115-135.

[50] Kirk D. Demographic transition theory. Population studies: A journal of Demography 1998;50(3):361-387.

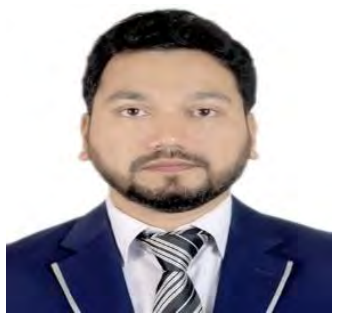

Dr. Md. Ashraful Babu is an Assistant Professor of the Department of Quantitative Sciences at the International University of Business Agriculture and Technology, Bangladesh. Dr. Babu had been awarded the degrees of Ph.D. (2019) in Mathematics from the Department of Mathematics, Jahangirnagar University, Bangladesh. Much of his work has been on improving the solution procedure, minimizing time complexity, and optimizing the total time and cost of transportation problems. Dr. Babu published several research articles in different international journals including OPSEARCH, Materials Today: Proceedings, Journal of Statistics \& Management Systems, etc.

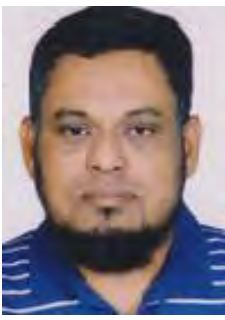

Dr. M. Mostafizur Rahman is basically a mathematician with extensive experience of mathematical modeling in multi-disciplinary environment. Dr. M. Mostafizur Rahman was born and brought up in Dhaka, Bangladesh. He completed his bachelor in mathematics and masters in applied mathematics from the University of Dhaka. He holds a PhD in information engineering from the University of Padova, Italy and worked as a post-doctoral research fellow for two years in the same University. He is serving as an Associate Professor in the department of Mathematics 